\title{
Erratum to: Roseovarius algicolus sp. nov., isolated from culture fluid of Cochlodinium polykrikoides
}

\author{
Saet-Byeol Moon · Sang-Seob Lee
}

Published online: 23 November 2015

(C) Springer International Publishing Switzerland 2015

\section{Erratum to: Antonie van Leeuwenhoek (2015) 108:1449-1456 DOI 10.1007/s10482- 015-0600-6}

In the original publication of the article, the spelling of Cochlodinium polykrikoides was published incorrectly in the title. The correct title is given in this erratum.
Further, the first and last sentences of the abstract have also been published incorrectly. The corrected sentences should read as, "A Gram-negative, aerobic, non-motile, catalase and oxidase positive rod-shaped bacterium, designated strain $4 \mathrm{CoA} 2^{\mathrm{T}}$, was isolated from Cochlodinium polykrikoides culture fluid in the laboratory" and "The type strain is $4 \mathrm{CoA} 2^{\mathrm{T}}$ (=JCM $30823^{\mathrm{T}}=$ KEMB 3501-068 $14^{\mathrm{T}}$ ).”

The online version of the original article can be found under doi:10.1007/s10482-015-0600-6.

\section{S.-B. Moon}

Department of Bio Technology, Division of Environmental \& Life Science, College of Natural

Science, Kyonggi University, 94-6 Iui-dong

Yeongtonggu, Suwon-si 443-760, Republic of Korea

\section{S.-S. Lee $(\bowtie)$}

Department of Life Science, School of Natural Science, Kyonggi University, San 94-6, Iui-dong, Yeongtong-gu, Suwon-si 443-760, Republic of Korea

e-mail: sslee@kyonggi.ac.kr 